\title{
Editorial
}

\section{On original articles and new beginnings}

This is the last editorial of my current term and I thank all my readers, authors, reviewers and Editorial Board both national and international for the wonderful support and feedback I got during this time. However it is not goodbye yet! You have elected me to a second term and I consider it a great honour. Looking back we have now achieved several things. Our journal is more widely read than ever beforeboth the print edition as well as online. The online version (www.ijps.org) is now accessed by over 250 visitors every day, which for a highly specialised journal is a very good number. This number is likely to increase further as we are planning to put back volumes of the journal online. Ninety percent of these visitors are from America and Europe, making our science visible to the world. We are indexed in several indices databases and bibliographic and are well on the way to be fully indexed-something that was holding back contributors for some time now. The international participation is now at $25 \%$ i.e., $25 \%$ of all submissions now come from authors outside India, a trend we welcome wholeheartedly and this is set to rise further as more submissions come from abroad. We were one of the first, internationally, to have a fully web based manuscript management site and the only plastic surgery journal to have a free, full text, web access. Medknow Publications and Dr. DK Sahu also richly deserve praise for these achievements.

The next step is to really upgrade content further and eventually have more issues. India is one of the most rapidly emerging economies now with a compound GDP growth rate of 7 to $8 \%$ for several years. This growth augurs well for India and therefore Indian Plastic Surgery. Eventually it will reflect in IJPS. I think with this issue we have made a beginning. IJPS is carrying truly original work by our colleagues from Karnataka- 'The Bangalore Classification of Craniofacial Anomalies'. This is solid work based on a large case load-something we always had, but more importantly meticulous documentation, collation and interpretation of data and finally the production of a manuscript for a journal. IJPS is happy to present this new classification to the world and we hope this is just the beginning of many more original contributions from around the world featuring in our journal.

I hope readers enjoy this issue and the ones to follow. We will strive to give you our best, with your support and active participation. Happy New Year to all.

Mukund Thatte

Editor, Indian Journal of Plastic Surgery 